\title{
Mikrobiyal Yakıt Hücrelerinde Kullanılan Saf Kültür Mikroorganizmaları ve Genel Özellikleri
}

\author{
Ahmet Erensoy ${ }^{1}$, Nurettin Çek $^{2 *}$ \\ ${ }^{1}$ Fırat Üniversitesi, Tıp Fakültesi, Parazitoloji Bölümü, Elazığ, Türkiye (ORCID: 0000-0001-6300-1105) \\ ${ }^{2}$ Fırat Üniversitesi, Mühendislik Fakültesi, Metalurji ve Malzeme Mühendisliği Bölümü, Elazığ, Türkiye (ORCID: 0000-0001-6120-9228)
}

(İlk Geliş Tarihi 5 Ocak 2020 ve Kabul Tarihi 7 Şubat 2020)

(DOI: 10.31590/ejosat.669787)

ATIF/REFERENCE: Erensoy, A., \& Çek, N. (2020). Mikrobiyal Yakıt Hücrelerinde Kullanılan Saf Kültür Mikroorganizmaları ve Genel Özellikleri. Avrupa Bilim ve Teknoloji Dergisi, (18), 109-117.

\section{$\ddot{O} \mathbf{z}$}

Biyokütle enerjisi, günümüzün artan enerji taleplerini karşılamakta kaçınılmaz bir görev yürüten yenilenebilir bir enerjidir. Biyoyakıtların aksine, mikrobiyal yakıt hücreleri organik malzemelerde toplanan enerjiyi doğrudan biyoelektrikliğe dönüştürür. Mikrobiyal yakıt hücreleri, kalkınma odaklı ve çok yönlü bir yenilenebilir enerji teknolojisidir. Mikrobiyal yakıt hücresi (MYH), çeşitli organik malzemelerden (substratlardan) elektrik enerjisi üretimi için kullanılan çevre dostu bir teknolojidir. Mikrobiyal yakıt hücreleri, doğrudan elektrik enerjisi üretimi için alternatif bir enerji dönüşüm sistemi olarak büyük ilgi görmektedir. Mikrobiyal yakıt hücreleri (MYH’ler), atık ortamda yakıt kaynağı olarak düşük dereceli organik karbonları kullanabilir. Mikrobiyal yakıt hücrelerinin, yakıt kaynağı olarak düşük dereceli biyokütle veya hatta atık su kullanabilmesinden dolayı belirgin faydaları vardır. Mikrobiyal yakıt hücrelerinde elektrik üretiminin temeli, organik malzemelerin mikroorganizmalar tarafindan katalize edilmesidir. Çünkü mikrobiyal yakıt hücreleri, organik maddeleri (substrat) oksitlemek için biyokatalizörler olarak mikroorganizmaları kullanır. Bir mikrobiyal yakıt hücresinde, organik maddeler (substratlar) elektron vericileridir. Organik malzemelerin oksidasyon (biyokataliz) çalışmalarından sonra anodik biyofilm bakterileri tarafindan açığa çıkarılan elektronlar ilk önce anoksik koşullar altında anot elektrota aktarılır. Bu işlemleri yapan bakterilere elektrojen denir. Anot elektrot, elektrojenik biyofilm bakterileri tarafindan anaerobik solunum için elektron alıcısı olarak kullanılır. Yani, anot ve mikroorganizma arasında bir elektron transfer işlemi gerçekleşir. Mikroorganizma ve elektrotlar arasındaki elektron transferi, doğrudan elektron transferi ve dolaylı (aracılı) elektron transferi olmak üzere iki mekanizmada gerçekleşir. Bu makalede, elektrojenik mikroorganizmalardan anot elektroduna elektron transfer mekanizması ayrıntılı olarak tartışılmıştır. Saf mikroorganizma kültürlerinin mikrobiyal yakıt hücrelerinde kullanımı anlatılmıştır. Bu makalenin sonuçlarına göre, yüksek elektrokimyasal aktivitelere sahip elektrojenik mikroorganizmaların keşfi, muhtemelen gelecekteki pratik sistem çalışmaları için mikrobiyal yakıt hücrelerinin gelişimini teşvik etmek için olağanüstü bir durum olacaktır.

(Minimum 250 - Maksimum 400 kelime ve içeriğinde amaç, materyal-metot, bulgular ve sonuç kısımlarını içerecek şekilde yazılmalidir.)

Anahtar Kelimeler: Mikrobiyal yakıt hücresi, Mikroorganizma, Elektron, Elektrik.

\section{Pure Culture Microorganisms Used in Microbial Fuel Cells and General Properties}

\begin{abstract}
Biomass energy is a renewable energy that running an unavoidable task in meeting today's ever increasing energy demands. Unlike biofuels, microbial fuel cells convert energy harvested at organic materials directly into bioelectricity. Microbial fuel cells (MFC's) are development-oriented as well-rounded a renewable energy technology. Microbial fuel cell (MFC) is an environmentally friendly technology used for electrical energy generation from a variety of organic materials (substrates). Microbial fuel cells have acquired
\end{abstract}

${ }^{*}$ Sorumlu Yazar: Fırat Üniversitesi, Mühendislik Fakültesi, Metalurji ve Malzeme Mühendisliği Bölümü, Elazığ, Türkiye, ORCID: 0000-0001-61209228, nurettincek001@gmail.com 
considerable interest as an alternative energy conversion system for direct electrical energy generating. Microbial fuel cells can utilize low-grade organic carbons as the fuel source in the waste environment. Microbial fuel cells (MFCs) have apparent benefits in that it can as fuel source utilize low-grade biomass or even wastewater. The basis of electricity generation in microbial fuel cells is the catalysed of organic materials by microorganisms. In a microbial fuel cell, organic materials (substrates) are electron donors. Microbial fuel cells use microorganisms as biocatalysts to oxidize organic materials (substrate). Electrons released by anodic biofilm bacteria after oxidation (biocatalysis) works of the organic materials are first transferred to the anode electrode under anoxic condition. The bacteria that make these processes are called electrogen. Anode electrode is used by the electrogenic biofilm bacteria as the electron acceptor for anaerobic respiration. So, an electron transfer process takes place between the anode and the microorganism. Electron transfer among microorganism and electrodes occurs on two mechanisms, namely direct electron transfer and indirect (mediated) electron transfer. In this article, electron transfer mechanism from electrogenic microorganisms to anode electrode is discussed in detail. The use of pure microorganism cultures in microbial fuel cells has been told. Suggestions have been made for the future status of electrogenic microorganisms in microbial fuel cells. According to these results of this article, reconnaissance of electrogenic microorganisms with high electrochemical activities would probably be an extraordinary status for promoting the development of microbial fuel cells for very presumably future practical system works.

(Minimum 250 - Maximum of 400 words and content should be written in a way to include material, method, findings and results.)

Keywords: Microbial fuel cell, Microorganism, Electron, Electricity.

\section{Giriş}

Yenilenebilir enerji üretim teknolojilerinden birisi de biyokütle enerjisidir. Biyokütledeki kimyasal enerji, mikrobiyal yakıt hücreleri sayesinde doğrudan elektrik enerjisine dönüştürülmektedir. Mikrobiyal yakıt hücresi (MYH), organik maddenin elektriğe doğrudan dönüştürülmesini sağlayan yenilikçi bir teknolojidir. Mikrobiyal yakıt hücrelerinde (MYH'lerde) organik madde bakteriler tarafından bozunarak elektron ve ve protonlar açığa çıkar. Bazı bakteri türlerinin doğal metabolizmalarının bir parçası olarak ortaya çıkan elektronlar bir anot elektrotuna geçerler. Anot elektrot, terminal elektron alıcısı olarak görev yapar. Elektronlar, anot elektrottan dış devre vasıtasıyla katot elektrota aktarılır. Açığa çıkan protonlar, çözelti (elektrolit) içerisinden katot elektrota göç ederler. Anottan gelen elektronlar, elektrolitten gelen protonlar ve havadan alınan oksijen katot elektrotta kimyasal tepkime sonucu birleşerek su oluştururlar. Böylece, mikrobiyal yakıt hücreleri (MYH'ler) elekrik enerjisi üretirler (Çek (2013); Çek (2016a); Çek (2017); Erensoy ve Çek (2018); Çek ve Erensoy (2019)).

MYH'ler, mikroorganizmaları katalizör olarak kullanan biyo tabanlı yakıt hücreleridir. Diğer yakıt hücrelerinin aksine, MYH'ler anotta değerli metal katalizörleri kullanmazlar. Bu nedenle, MYH teknolojisi, ucuz bir şekilde elektriksel güç üretmek için yeni ve umut verici bir yaklaşımı temsil etmektedir (Cao ve ark. (2019)). Mikroorganizmalar tarafından elektrik akımı üretimi kavramı 100 yıldan fazla bir süredir ortaya çıkarılmıştır. Elektrik üretimi için MYH cihazları yaklaşık 50 yıldır yoğun bir çalışma altında geliştirilmektedir. MYH'ler, elektrolitler tarafından ayrılan iki elektrot, bir anot ve bir katottan oluşan diğer herhangi bir pil veya yakıt hücresine benzer. Aradaki fark, elektrik üretmek için substrat (ayrışan madde) olarak organik bileşikler kullanmasıdır (Cao ve ark. (2019)). Organik maddenin enerji içeriği, organik maddenin bakteriler tarafindan parçalanma performansı, bakterilerin elektrotlarla uyumluluğu gibi faktörler mikrobiyal yakıt hücrelerinin elektrik üretim performansını belirleyen esas faktörlerdendir (Çek ve Erensoy (2019); Pareek ve ark. (2019)).

Organik bileşikleri oksitleyen ve elektronları MYH'lerin anotlarına aktaran mikroorganizmalara "elektrokimyasal olarak aktif mikroorganizmalar, electricigen (elektrikjen), elektrojen veya electrogenic (elektrojenik)" denir. Bunlar, MYH'lerin enerji üretim mekanizmalarında net bir ayrım yapmak için ortaya çıkmıştır. Electricigens mikroorganizmaları sayesinde üretilen elektrik, diğer mikroorganizmalara göre oldukça farklıdır. Bir MYH sisteminde, anotun yakın çevresinde kullanılan electricigen, elektrik üretim performansını etkileyen temel faktörlerden biridir (Cao ve ark. (2019); Chen ve ark. (2018); Haavisto ve ark. (2019)).

$\mathrm{Bu}$ çalışmada, electrikjen mikroorganizmalarından anoda elektron aktarım mekanizması ayrıntılı olarak ele alınmıştır. Saf kültürlerin MYH'lerdeki kullanımı anlatılmıştır. MYH'lerdeki elektrikjen mikroorganizmaların gelecekteki durumları için önerilerde bulunulmuştur.

\section{Elektrikjen'lerden Elektrota Elektron Aktarım Mekanizmaları}

Elektrikjenlerin solunum zincirinden elektrota elektron aktarımı işi MYH teknolojisi için çok önemlidir. Çünkü elektron, elektriksel ve kimyasal etkileşimi gerçekleştirmektedir (Çek (2016b)). Mikroorganizmalar tarafindan elektron transferi süreci doğal bir fenomen değildir. Bu mekanizma henüz tam olarak aydınlatılmamış olmasına rağmen, elektrikjenlerin elektrotlara elektron transferi için çok sayıda yol önerilmiştir. Genel olarak, bu mekanizmalar iki tipe ayrılabilir. Bunlar; doğrudan elektron aktarımı (hücre yüzeyi ile elektrot arasında doğrudan temas) ve dolaylı elektron aktarımı (sözde elektron aracıları aracılığıyla) olarak ifade edilmiştir (Cao ve ark. (2019)). Elektrikjenler tarafından anot elektrota elektron aktarımı Şekil 1'de gösterilmiştir. 


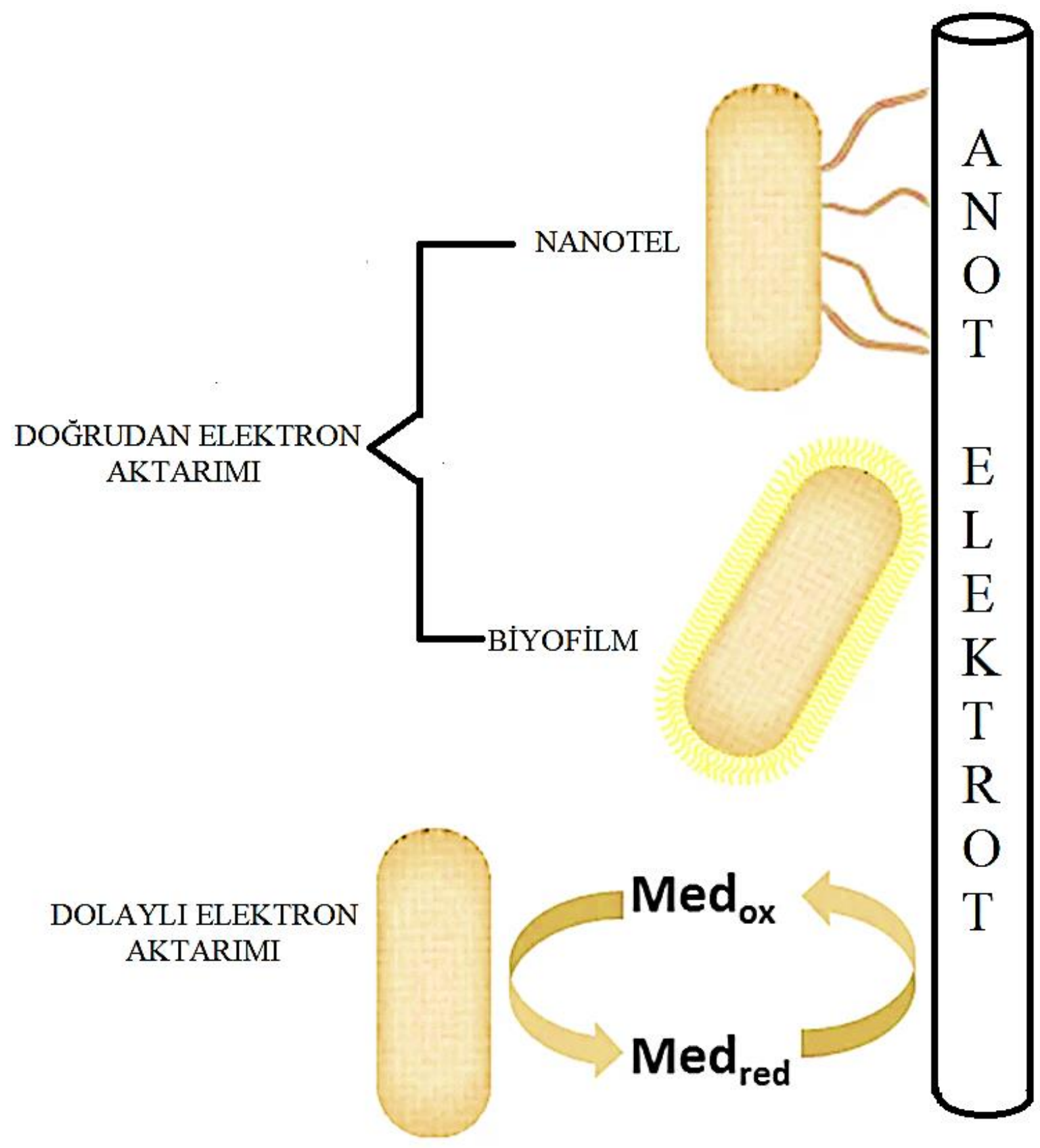

Şekil 1. Elektrikjen'lerden anoda elektron aktarım mekanizmaları (Cao ve ark. (2019)).

Doğrudan elektron aktarımı, herhangi bir dağılabilir redoks bileşiğini içermeden hücre ve bir elektrot arasında doğrudan fiziksel bir temas yoluyla meydana gelebilir. Elektrikjen mikroorganizmalar anot yüzeyinde biyofilmler veya elektriksel olarak iletken nanoteller (pili ve flagella) oluştururlar. Elektron transferi, dış zar sitokromu ve nanotelleri veya trans-membran elektron taşıma proteinleri yoluyla herhangi bir difüzyonel elektron aracısı olmadan doğrudan temas yoluyla gerçekleşir. Nanoteller membrana bağlı sitokromlara bağlanır ve elektrikjenlerin elektron alııısı olarak doğrudan hücre teması olmayan bir elektrot kullanmasına izin verir. Elektron taşıma proteinleri, elektronları sitoplazmadan dış membrana ve son olarak anoda aktarırken doğrudan elektron transferinde önemli bir rol oynar. Doğrudan elektron transferi, MYH'lerde verimli akım üretimi için ilk tercihtir. Doğrudan elektron transferinin sınırlandırılması, elektron taşıma proteinlerinin aktif bölgelerinin tipik olarak proteinlerin içine gömülmesidir. Bu da zayıf elektron transfer hızıyla sonuçlanır. Mikroorganizmadaki hücre zarı veya hücre zarının dış yüzeyinde redoks aktif proteinleri mevcutsa ve bu proteinler, elektronların hücre içi ile dış bir ortam arasında taşınmasına izin veriyorsa ve de hücrelerin elektrot yüzeyine yakın fiziksel teması varsa doğrudan elektron aktarımı gerçekleşir. Bu proteinlere örnek olarak; Sitokromlar, flavoproteinler veya çoklu bakır proteinleri verilebilir Şimdiye kadar, Shewanella ve Geobacter gibi sadece birkaç elektrokimyasal olarak aktif bakteri türünün, elektronları hücreden anota aktaran bakteriyel nanoteller oluş̧urduğu tespit edilmiştir. Geobacter, bir biyofilmin uzak iç katmanlarından elektronları $10 \mu \mathrm{m}$ 'ye kadar ileten iletken hücre uzantıları, nanoteller veya pili yoluyla uzun menzilli doğrudan elektron transferi oluşturabilir. Bununla birlikte, verimlilik, bakteriyel tek tabakadaki maksimum hücre yoğunluğu ile sinırlıdır. Bakteriyel tek tabakadaki hücre yoğunluğu artışı daha kalın bir elektrokimyasal olarak aktif bakteriyel çok tabakalı ve daha yüksek bir doğrudan elektron transferi verimi geliştirilmesini sağlar. Nanotellerin moleküler yapısı henüz deneysel olarak tam olarak tanımlanmamıştır ve elektronların bir pilus boyunca aktarıldığı mekanizma tam olarak anlaşılamamıştır. Nanotellerde önerilen iletkenlik modelleri, çok aşamalı elektron atlamalı ve metal benzeri iletken mekanizmalar olup bunlar aktif olarak tartışılmaktadır 
(Cao ve ark. (2019); Chen ve ark. (2019); Light ve ark. (2018); Malvankar ve Lovley (2012); Pankratova ve ark. (2019); Pirbadian ve ark. (2012); Zhao ve ark. (2009)).

Ayrıca bazı çalışmalarda, Desulfobulbaceae familyasından yaşayan canlı bakterilerin tortusu için yeni bir hücreden hücreye elektrik bağlantısı önerilmiştir. Bu bakterilerin binlerce hücreden oluşan çok hücreli teller oluşturduğu ve hücre zincirinin terminal ucundaki oksijenin azaltılmasını ve sülfürlerin oksidasyonunu bağlayarak istisnai santimetre ölçekli mesafeler boyunca tüm filament (tel) boyunca hücreler arası doğrudan elektron transferini gerçekleştirmeleri beklenir. Bu olağanüstü uzun menzilli doğrudan elektron transferinin moleküler mekanizmaları şu anda bilinmemektedir (Nielsen ve ark. (2010); Pankratova ve ark. (2019); Pfeffer ve ark. (2012))

Dolaylı elektron transferi, indirekt veya aracilı (mediated) elektron transferi olarak da ifade edilir. Dolaylı elektron transferi, hücre ve elektron alıcısı (anot) arasında doğrudan temas gerekliliğini ortadan kaldıran düşük molekül, çözünür aracılar yardımıyla sağlanır. Bir başka deyişle, dolaylı elektron transferi harici bir verici/akseptör ile bir mikroorganizma arasında elektronları tutan redoks aktif aracı bileşiklerin varlığıyla gerçekleşir. Elektron aracıları, bakteri hücrelerine girebilir, elektronların metabolik reaksiyonlarından elektronları çıkarabilir ve bu elektronları bir MYH anoduna sağlayabilir. Dolaylı elektron transferi işlemi, sisteme veya bir mikrop tarafindan salgılanan metabolitlere eklenen yapay bir arabulucu olabilen aracılık yapan redoks türlerinin doğasına ve kaynağına bağlı olarak çeşitli şekillerde gerçekleştirilebilir. Bakteriler, elektron aktarımına yayılabilir aracılar olarak dahil olabilen çeşitli birincil ve ikincil metabolitleri salgılarlar. Bazı mikrobiyal türler, bir elektron akışı üreten elektrot yüzeyinde oksitlenebilen bir dizi azaltılmış birincil metabolit olarak örneğin; $\mathrm{H}_{2}$ veya $\mathrm{H}_{2} \mathrm{~S}$ üretirler. Redoks mediatörleri olarak işlev gören düşük moleküler ağırlıklı sekonder metabolitlerin örnekleri de; Pseudomonas aeruginosa bakterileri tarafindan üretilen fenazinler, Shewanella oneidensis bakteriler tarafindan tatlandırılan fenazinler ve Lactococcus lactis bakterileri tarafindan ortaya çıarılan kuinonlardır. Anodik işlemlerle ilgili olarak, doğal bir dağılabilir aracı, bakteriyel sitoplazmik zarda serbest bırakılan elektronların yardımıyla azaltılabilir ve elektrot yüzeyinde yeniden oksitlenecek anoda yayılabilir ve böylece elektronlar iletilebilir. Böyle bir mekik aktivitesi, biyofilmin daha derin hücre katmanlarını elektrot yüzeyi ile temas ettirir. İşlem tersine çevrilebilir ve aracı türler birçok kez redoks döngüsüne girebilir. Böylece, az miktarda atılan redoks aktif metabolitleri bile elektron aktarımını kolaylaştırabilir. Ayrıca, bir mikrop tarafından atılan bir aracı, başka bir mikrobiyal türün elektron aktarımını destekleyebilir ve böylece mikrobiyal konsorsiyumda mevcut üretimin verimliliğini artırılabilir. Mikroorganizmalar genellikle peptitoglikan, lipopolisakkaritler ve elektron aktarımını önleyen lipit çift katmanları gibi esasen elektron olmayan iletken malzemelerden oluşan bir hücre zarına sahiptir. Dış aracılar bu sınırın üstesinden gelebilir ve mikrobiyal metabolizmayı elektron aktarımını sağlayan bir elektroda etkili bir şekilde bağlayabilir. Bununla birlikte, etkinlik redoks mediatörünün doğasına bağlı olarak değişir. İdeal bir arabulucu belirli gereksinimleri karşılamalıdır. Bu gereksinimler; iyi çözünürlük, hem oksitlenmiş $\left(\operatorname{Med}_{\mathrm{ox}}\right)$ hem de indirgenmiş $\left(\mathrm{Med}_{\mathrm{red}}\right)$ formlarında uzun süreli stabilite, biyolojik olarak bozunamazlık, mikroorganizmalar için toksik olmama ve yüksek heterojen elektron aktarımı oranına sahip iyi tanımlanmış geri dönüşümlü voltametrik yanıt olarak belirtilmektedir. Arabulucular ve redoks proteinleri arasındaki potansiyel fark, elektron transferinin etkinliğini önemli ölçüde etkileyecektir. Hem inorganik hem de organik bileşikler elektron transferini arttırmak için araştırılmıştır. Bu bileşiklere örnek olarak; hümik asit, metilen mavisi, antrasendion, potasyum ferrisiyanid, flavinler, kinonlar, nötr kırmızı ve tiyonin dahil olmak üzere çok çeşitli difüze edilebilir arabulucu bileşikler tanımlanmışıtır. Bununla birlikte, ekzojen aracıların eklenmesi, her zaman nispeten düşük akım yoğunluklarına yol açtıkları ve mikroorganizmalar için pahalı ve toksik oldukları için tercih edilmez, çünkü uzun zaman periyotlarında performansın düşmesine neden olur, bu da tekniğin ticarileştirilmesini zorlaştırır. Ayrıca, ekzojen aracıların düzenli olarak eklenmesi teknolojik olarak olanaksızdır ve çevresel olarak sorgulanabilir. Bu nedenle, mikroorganizma ekzojen aracılar eklenmeden bir katalizör olarak verimli bir şekilde kullanılabiliyorsa, teknik açıdan çevresel açıdan güvenli olmanın yanı sıra aşamalı olarak elektron aracılarının eklenmesine gerek yoktur. Lipidde çözünebilir veya çözünmez olmalarına bağlı olarak farklı verimliliklere sahip olmaları beklenir. MYH'lerde en çok araştırılan aracılar olarak fenazinler, fenoksazinler, fenotiyazinler ve kinonlar karşımıza çıkmaktadır. Bununla birlikte, harici olarak eklenen arabulucular, genellikle kararsız ve toksik olup aynı zamanda, serbesţ̧e yayılan redoks servislerinin düzenli bir şekilde tedarik edilmesini gerektirmektedir. $\mathrm{Bu}$ da bu yaklaşımı teknolojik olarak elverişsiz kılmaktadır ve çevre dostu değillerdir. Gerekli olan tüm aktif bileşenlerin bir elektrot yüzeyinde güvenli bir şekilde hareketsizleştirildiği yeni yenilikçi yaklaşımların geliştirilmesi gerektiği açıktır (Cao ve ark. (2019); Chen ve ark. (2019); Evelyn ve ark. (2014); He ve ark. (2017); Pankratova ve ark. (2019); Patil ve ark. (2012)).

\section{Anotta Elektrikjen Olarak Bulunun Saf Kültürlü Mikroorganizmalar}

MYH'lerde biyokatalizör olarak elektrikjenlerin kullanımı vazgeçilmez hale gelmiştir. Şimdiye kadar, yüzlerce elektrikjen izole edildi ve MYH'lerde kullanıldı. Bu elektrikjenlerin çoğu Proteobacteria ve Firmicutes'a aittir. Son çalışmalar, MYH'lerde bulunan elektrikjenlerin farklı bir eğilime sahip olduğunu göstermiştir. Elektrik üretme özelliklerine sahip mikroorganizmalar hala keşfedilmeyi beklemektedirler (Cao ve ark. (2019)). Elektrikjenlerin çeşitliliğini ve benzerliğini daha iyi anlamak için, mevcut elektrik üreten mikroorganizmaları sistematik olarak özetlemek gerekir. MYH’lerden izole edilmiş NCBI (National Center for Biotechnology Information) Taksonomi veritabanına göre farklı suşların bir özeti Tablo 1'de verilmiştir. 
European Journal of Science and Technology

Tablo 1. MYH'lerin anotlarında kullanılan elektrikjenlerin saf kültürleri

\begin{tabular}{|c|c|c|c|}
\hline Tip & Cins & Tür & Kaynak \\
\hline Arke & Haloferax & H. volcanii & Abrevaya ve ark. (2011). \\
\hline Arke & Natrialba & N. magadii & Abrevaya ve ark. (2011). \\
\hline Asidofilik & & Geothrix fermentans & Cao ve ark. (2019). \\
\hline Siyanobakteri & Synechocystis & Synechocystis PCC-6803 & Ma ve ark. (2012) \\
\hline Siyanobakteri & Spirulina & S. platensis & Fu ve ark. (2010). \\
\hline Siyanobakteri & Nostoc & Nostoc sp. ATCC 27893 & Sekar ve ark. (2014). \\
\hline Firmicutes & Clostridium & C. beijerinckii & Liu ve ark. (2015). \\
\hline$\alpha$-Proteobakteri & Rhodospirillum & R. rubrum & Gomez ve ark. (2014). \\
\hline$\alpha$-Proteobakteri & Rhodobacter & R. sphaeroides & Cho ve ark. (2008). \\
\hline$\alpha$-Proteobakteri & Rhodopseudomonas & R. palustris & Xing ve ark. (2008). \\
\hline$\alpha$-Proteobakteri & Ochrobactrum & O. anthropic & Zuo ve ark. (2008). \\
\hline$\alpha$-Proteobakteri & Acidiphilium & A. cryptum & Borole ve ark. (2008). \\
\hline$\beta$-Proteobakteri & Rhodoferax & R. ferrireducens & Liu ve $\operatorname{Li}(2007)$. \\
\hline$\gamma$-Proteobakteri & Escherichia & E. coli & Xiang ve ark. (2009). \\
\hline$\gamma$-Proteobakteri & Shewanella & S. putrefaciens & Qiao ve ark. (2014). \\
\hline$\gamma$-Proteobakteri & Shewanella & S. oneidensis & Lapinsonnière ve ark. (2013). \\
\hline$\gamma$-Proteobakteri & Pseudomonas & P. aeruginosa & Shreeram ve ark. (2018). \\
\hline$\delta$-Proteobakteri & Geobacter & G. sulfurreducens & Yi ve ark. (2009). \\
\hline$\delta$-Proteobakteri & Geobacter & G. metallireducens & Liu ve ark. (2004). \\
\hline$\delta$-Proteobakteri & Geopsychrobacter & G. electrodiphilus & Holmes ve ark. (2004). \\
\hline Maya & Saccharomyces & S. cerevisiae & Raghavulu ve ark. (2011). \\
\hline Maya & Candida & C. melibiosica & Hubenova ve Mitov (2010). \\
\hline Maya & Arxula & A. adeninivorans & Haslett ve ark. (2011). \\
\hline Ökaryotik algler & Chlamydomonas & C. reinhardtii & Lan ve ark. (2013). \\
\hline Ökaryotik algler & Chlorella & C. pyrenoidosa & Xu ve ark. (2015). \\
\hline Ökaryotik algler & Chlorella & Chlorella sp. UMACC 313 & Ng ve ark. (2014). \\
\hline
\end{tabular}

Birçok arkea tipi mikroorganizma, diğer mikroorganizmalara muazzam bir stres uygulayan yüksek sıcaklık ve tuzluluk gibi aşırı stresli ortamlarda hayatta kalabilir. Özel koşullar altında MYH'lerde elektrikjen madde olarak hizmet etme potansiyeline sahiptirler. İki halofilik arkea türü olan Haloferax volcanii ve Natrialba magadii, bir MYH anotunda elektrikjen olarak test edildi. Bu bakteriler, MYH'lerin elektriksel güç yoğunlukları için faydalı olmuşlardır. Bu bakterilerin olduğu ortama elektron aracı olarak nötr kırmızı maddesi eklendiğinde, MYH'lerin elektriksel güç yoğunlukları daha da iyileştirilmiştir (Abrevaya ve ark. (2011); Cao ve ark. (2019)). 
Asidobakteriler fizyolojik olarak çeşitli asidofilik bakterilerdir. Çeşitli ortamlarda bulunabilirler ve çok çeşitli alt tabakaları kullanabilirler. Bu filumun birkaç üyesi elektrokimyasal aktivite göstermiştir. Özellikle, demir azaltıcı bakteriler olan Geothrix fermentans, elektrotta indirgeme reaksiyonunu teşvik eden elektron aracılarını ortaya çıkarmıştır. Bu bakteriler, MYH'lerin elektriksel güç çıkışları için faydalı olmuşlardır (Ahmed ve ark. (2019); (Cao ve ark. 2019)).

Siyanobakteriler, fotosentetik mikroorganizmalardır ve biyoenerji üretimi için çevre dostu kaynaklardır. Son yıllarda, birçok çalışma MYH'lerde siyanobakterilerin kullanılması üzerine odaklanmışıı. Siyanobakterilere dayanan biyoelektrokimyasal sistemlerde, siyanobakteriler 1şıkta fotosentez yaparak elektrik üretirler. Siyanobakterleri kullanarak elektrik üreten MYH'lere fotosentetik MYH'ler denir. Fotosentetik MYH'lerde elektrikjen olarak kullanılan bazı siyonobakteriler şunlardır: Synechocystis, Spirulina platensis, Nostoc. Bunlarla birlikte, bir siyanobakteri olan Synechococcus elongatus bakterisinin de MYH'ler elektrikjen olarak kullanılmasına yönelik çalışmalarda vardır. Ayrıca, fotosentetik MYH’ler ile ilgili yapılan çalışmalarda, elektron aracısı olarak 1,4-benzokinon eklendiğinde, MYH'nin güç üretim kabiliyetinde önemli bir iyileşme olduğu gözlenmiştir (Cao ve ark. (2019); Fu ve ark. (2010); Hassani ve ark. (2019); Ma ve ark. (2012); Sekar ve ark. (2014)).

Firmicutes tipi mikroorganizmalar kalın hücre duvarlarına sahiptir ve zorlu koşullara toleranslıdır. Her zaman MYH'lerin anotunda yer alan karışı kültürlerden izole edilebilirler. Bununla birlikte, MYH'nin elektrik üretebilmesi için elektronların Firmicutes'lerin hücre duvarından anota geçmesi gerekir. Firmicutes'lerin hücre duvarları kalın olduğu için nispeten daha düşük elektrokimyasal aktivite gösterirler. Firmicutes'ler anaerob (oksijensiz) ortamlarda, geniş bir pH ve sıcaklık aralığında büyüyebilirler. C. Beijerinckii, Thermincola sp. strain, MYH'lerde en çok kullanılan Firmicutes tipi bakterilere örnek olarak verilebilir. İlaveten, metanolle beslenen bir MYH'de, yeni bir Firmicutes türü izole edildi ve bu türün 16S rRNA gen filogenetik analizi sonucu Methylomusa anaerophila olduğu belirlendi (Amano ve ark. (2018); Cao ve ark. (2019); Liu ve ark. (2015)).

Bazı $\alpha$-proteobakteri türleri fototrofik bakterilerdir. Bu nedenle fotosentetik MYH'lerde de elektrikjen olarak kullanılabilirler. fotosentetik MYH'de kullanılan ilk bakteri şuşu Rhodospirillum rubrum bakterisidir. Rhodobacter cinsinin üyeleri fotosentetik MYH'ler için iyi biyokatalizörlerdir. Bunlar arasında $R$. sphaeroides en etkili olanıdır. $R$. Sphaeroides'in MYH'de mevcut elektrik üretim kabiliyeti genetik modifikasyon ile daha da geliştirilmiştir. $R$. Capsulatus bakterisinin fotosentetik MYH'lerde elektrik üretim performansı da araştırıldı, ancak mevcut güç yoğunluğu diğer türlere kıyasla çok daha düşük değerlerde gerçekleşmiştir. Rodopseudomonas biyohidrojen üretimi için kullanılabilir ve ayrıca elektrik üretme potansiyeline sahiptir. MYH'de anodik biyokatalizör olarak $R$. palustris bakterisi de kullanılmıştır. $R$. palustris nitrojenazının nakledilmesi, güç kaynağının ve elektrik üretim kapasitesinin azalmasına engel olmuştur. Başka bir $\alpha$-proteobakteri olan ochrobactrum anthropi, özel bir U tüpü şeklindeki MYH uygulamasında kullanılmıştır. Asidofilik bakteri olan acidiphilium cryptum kullanılan MYH'de nispeten düşük pH değerinde elektrik üretimi gerçekleştirilmiştir. Daha sonra MYH'nin güç çıkışı elektron aracıları yardımıyla arttırılmışıtır (Cao ve ark. (2019); Gomez ve ark. (2014); Borole ve ark. (2008); Cho ve ark. (2008); Xing ve ark. (2008); Zuo ve ark. (2008)).

Rhodoferax ferrireducens, bir MYH'de elektrikjen olarak rapor edilen tek $\beta$-proteobakteridir. Elektronu $\mathrm{Fe}^{3+}$ iyonunna aktarabilen fakültatif bir anaerobdur. Bir $R$. ferrireducens kullanılan MYH sisteminde elektron aracıları gerekli değildir (Cao ve ark. (2019); Liu ve $\mathrm{Li}(2007))$.

$\gamma$-Proteobacteria en çok incelenen elektrikjenlerdir. Yapılan araştırmalarda, MYH'de, $\gamma$-proteobacteria türü olan Escherichia coli elektrikjen olarak kullanılmıştır. E. coli, iyi karakterize edilmiş bir model mikroorganizmadır. Örneğin; açık genetik arka plan, genetik olarak değiştirilme kolaylığı ve düşük besin gereksinimleri olan hızlı büyüme özelliği gibi birçok avantaja sahiptir. MYH'nin elektrik üretim yeteneğini geliştirmek için mühendisler, E. coli'ye genetik araçlar uygulanmıştır. Anaerobik koşullar altında, E. coli'nin trikarboksilik asit (TCA) döngüsü baskılanmış, bu nedenle MYH'de düşük güç üretim verimliliğine yol açtı. Sonra, TCA döngüsünün bir inhibitörünü kodlayan arcA geninin nakavt edilmesi sonucu MYH’nin performansı ve güç çıkışı büyük ölçüde artmıştır. Endojen gliserol dehidrojenaz, anodik biyokatalizör olarak bir suş oluşturmak üzere E. coli'de aşırı eksprese edilmiştir. Bu tasarlanan suş, E.coli hücreleri ile elektrot arasında elektron transferini destekleyen elektron aracılarını sentezleyebilmektedir. E. coli'nin laktik asit yolunun bozulması, hücre içi indirgeme gücü seviyesini ve elektron üretimini arttırmıştır. Bu elektronlar serbest bırakıldı ve daha sonra anoda aktarılmıştır. Böylece, MYH daha yüksek elektriksel güç çıkışı sağlamıştır. $\gamma$-proteobakterilerin diğer önemli elektrikjenleri Shewanella ve Pseudomonas'tır. Shewanella, iyi karakterize edilmiş elektron transfer mekanizmaları nedeniyle MYH'lerde yaygın olarak kullanılmaktadır. Shewanella putrefaciens, elektrotlarında aracı olamayan bir MYH oluşturmak için kullanılan ilk bakteri suşudur. Demir ve manganez gibi metal iyonlarını indirgeyebilen (azaltabilen) fakültatif bir anaerobdur. Yapılan çalışmalarda, bu suşu bir MYH'ye uygulanmış ve substrat olarak laktat kullanılarak elektrik üretilebileceği tespit edilmiştir. Son zamanlarda yapılan çalışmalarda bakteri hücrelerinin elektroda yapışmasını iyileştirmek için düzgün nanoflaky nikel oksit dizi kaplama stratejisi kullanılmıştır. S. putrefaciens kullanılan MYH'nin elektriksel güç performansı artmıştır. Shewanella strains, Shewanella suşlarının potansiyeli olarak değerlendirildi ve $S$. oneidensis en iyi kabiliyeti göstermiştir. Bu türün iki alt türü, $S$. oneidensis DSP10 ve S. oneidensis MR-1, farklı MYH'lerde yaygın olarak kullanılmıştır. Pseudomonas aeruginosa, elektron mediatörlerini sentezleyebilen bildirilmiş en erken suştur. Dahası, P. aeruginosa genetik olarak manipüle edilebilir. P. Aeruginosa'daki elektron aracılarının biyosentezi, 2-heptil-3,4-dihidroksikinolin çekirdek algılama sistemi tasarlanarak geliştirilmiştir. $P$. Aeruginosa'da ve G. Sulfurreducens'de PilA (protein liflerini nanoteller oluş̧urmak üzere kodlayan yapı geni) ifadesi, iletkenliği doğal G. sulfurreducens ile karşılaştırılabilir olan piliyi vermektedir. Bir ATPase'yi kodlayan pilT geni, nakavt edildiğinde pili sayısını artırabilir. P. aeruginosa'nın pilT mutantı hiperpiliasyona uğrayabilir. Böylece, MYH'nin elektriksel güç yoğunluğu artmıştır (Cao ve ark. (2019); Lapinsonnière ve ark. (2013); Xiang ve ark. (2009); Qiao ve ark. (2014); Shreeram ve ark. (2018)).

$\delta$-Proteobacteria, birçok MYH'de uygulanabilen iki önemli bakteri nesli olan Geobacter ve Geopsychrobacter içerir. Geobacter, elektron donörleri olarak çeşitli organik bileşikler kullanır ve $\mathrm{Fe}^{3+}$ maddesini indirger (azaltır). Gram-negatif kükürt azaltıcı bir bakteri olan G. sulfurreducens, MYH uygulamalarında şimdiye kadar izole edilen elektriklijenler arasında en yüksek elektrik akımını 
üretmiştir. Bu bakteri, elektrota bağlanabilir ve uzun süre canlı kalabilir. G. metallireducens bakterisi MYH cihazlarından izole edilen verimli bir elektrikjendir. Pirinç çeltik tarlalarında faaliyet gösteren tortu tipi MYH'lerdeki anodik toplulukların \% 90'ını oluşturmaktadır. G. metallireducens içeren MYH'ler hem elektrik üretmekteler hem de atık su arıtımı yapabilmektedirler. Geopsychrobacter electrodiphilus, denizel tortu MYH'lerden izole edilen önemli bir elektrikjendir. Bu bakteri nispeten düşük sıcaklıkta büyüyebilir ve çeşitli organik substratları kullanabilir (Cao ve ark. (2019); Holmes ve ark. (2004); Liu ve ark. (2004); Yi ve ark. (2009)).

Ökaryotlar üzerinde MYH’ler için katalizör olarak nispeten az sayıda çalışma vardır. Mayalar, net genetik geçmişleri, hızlı büyüme oranları ve genel olarak güvenli oldukları için elektrikjen olarak iyi adaylardır. Saccharomyces cerevisiae MYH'de elektrik üretimi için test edilmiştir. Maya MYH’leri hala bakteriyel MYH'lerden daha düşük bir güç çıkışı üretse de, yeni çalışmalarda ilgi görmektedirler. Mükemmel elektrokimyasal aktiviteye sahip tasarlanmış bir S. cerevisiae suşu, hücre yüzeyinde glikoz oksidaz sergilemiş ve MYH, modifiye edilmemiş mayadan daha yüksek güç çıkışı ve akım yoğunluğu göstermiştir. Son zamanlarda yapılan bir çalışmada, S. cerevisiae elektrik üretimi ve substratların farklı redoks koşulları altında bozulmasını değerlendirmek için elektrikjen olarak kullanılmıştır. Anot olarak grafit kullanılarak, eksojen aracıların yokluğunda tek odacıklı MYH'de daha yüksek akım ve güç yoğunlukları elde edilmiştir. Maya ekstraktı, S. cerevisiae içeren MYH'de elektron aracısı olarak başarıyla uygulanmıştır. Maya ekstraktının eklenmesi, maya hücrelerinin anot elektrota yapışmasını artırabilir. Bunun sonucunda, çift odacıklı MYH'deki maksimum akım yoğunluğu ve güç yoğunluğu artmıştır. Başka bir maya suşu olan Candida melibiosica da MYH'ler için biyokatalizör olarak kullanılmıştır. $C$. melibiosica yüksek fitaz aktivitesine sahiptir ve herhangi bir ekzojen elektron aracısı olmadan elektrik üretebilir, bu da bu suşun bir elektrikjen olduğunu kanıtlar. Maya türü olan Hansenula anomala'nın hareketsizleştirilmiş hücreleri de aracısız bir MYH'de elektrikjen olarak hareket etme kabiliyeti açısından test edilmiş ve MYH sisteminde verimli akım üretimi gözlemlenmiştir. Hücre zarlarında redoks proteinlerinin varlığının MYH'de doğrudan elektron transferine katkıda bulunduğu düşünülmüştür. Geleneksel olmayan maya olan Arxula adeninivorans, MYH katalizörü olarak kullanılmıştır. İndirgeyici moleküllerin salgılanması yoluyla elektronları anoda aktarabildiği anlaşılmıştır. A. adeninivorans kullanılan MYH’deki maksimum güç yoğunluğu diğer MYH'lere kıyasla daha yüksek olmuştur. Bu nedenle, A. adeninivorans kullanılan MYH, diğer MYH'lere göre daha etkili MYH'lerden biridir (Haslett ve ark. (2011); Hubenova ve Mitov (2010); Raghavulu ve ark. (2011)).

Alg biyokütlesi her zaman MYH'lerde elektrikjen bakteriler için substrat görevi görür. Ayrıca algler hem anotta elektron verici hem de katotta elektron alıcı olarak kullanılabilir. Çoğu durumda, algler MYH'lerin katotuna yerleştirilir. Çünkü oksijen $\left(\mathrm{O}_{2}\right)$ üreterek katodik reaksiyonu kolaylaştırırlar ve karbondioksit $\left(\mathrm{CO}_{2}\right)$ kullanabilirler. Şimdiye kadar, MYH'lerde yalnızca Chlamydomonas reinhardtii ve Chlorella $s p$. anodik haznede elektrikjen olarak test edilmiştir. Model mikroalg olan $C$. reinhardtii, fotosentetik MYH'ler farklı 1şık yoğunlukları karşılaştırılarak araştırılmıştır. Kırmızı LED 1şığı, fotosentetik MYH'nin mavi 1şıktan daha yüksek bir güç yoğunluğu üretmesini sağlamıştır. Işık yoğunluğu ne kadar yüksek olursa, fotosentetik MYH'nin elektriksel performansının o kadar iyi olduğu görülmüştür. Yeşil alg olan Chlorella pyrenoidosa da bir fotosentetik MYH'nin anotuna sokulmuştur. Kültür koşulları kontrol edilerek, bu alg türünün MYH'de harici olarak eklenmiş substratlar olmadan elektrik üretebileceği görülmüştür. Yeni izole edilmiş bir Chlorella sp. UMACC 313 anot üzerinde biyofilm oluşturmak için kullanılmıştır. Fotosentetik MYH'deki maksimum güç ve akım yoğunluğu artmıştır. Algler ayrıca bir MYH içindeki aljinat jelinde hareketsizleştirilmiş ve pik güç çıkışı ile akım yoğunluğunun daha da arttığı görülmüştür (Cao ve ark. 2019; Kondaveeti ve ark. (2014); Lan ve ark. (2013); Ng ve ark. (2014); Xu ve ark. (2015)).

\section{Sonuçlar ve gelecekteki olası durumlar}

Mikrobiyal yakıt hücresi (MYH) cihazlarında, elektrikjen olarak adlandırılan mikroorganizmalar biyokatalizör olarak kullanılmaktadırlar. Elektrikjen mikroorganizmalar, organik malzemeleri (substratları) ayrıştırarak organik malzemelerin sahip oldukları kimyasal enerjiyi açığa çıkarmaktadırlar. Açığa çıkan bu kimyasal enerji nedeniyle elektron ve protonlar açığa çıkmaktadır. Elektronların anot elektrota gidip oradan diş devreyi kullanarak katot elektrota gitmektedirler. Protonlar elektrolit içerisinden katot elektrota gitmektedirler. Anottan gelen elektronlar, katota gelen protonlar ve havadan alınan oksijen kimyasal olarak birleşerek su açığa çıkarmaktadırlar. Böylece, MYH’ler ile doğrudan elektrik enerjisi üretilmektedir (Cao ve ark. (2019); Chen ve ark. (2018); Çek (2016a); Çek (2017); Erensoy ve Çek (2018); Çek ve Erensoy (2019); Pareek ve ark. (2019); Zuo ve ark. (2008)).

MYH teknolojisi son birkaç yılda oldukça gelişmiştir. Bununla birlikte, MYH’lerin elektriksel güç çıkışlarının sınırlamaları nedeniyle henüz MYH'lerin pratik uygulamaları yoktur. Elektrikjen mikroorganizmalar MYH sistemlerindeki temel sorunlardan birisidir. Elektrikjenlerin uygulanması, MYH'ler için gelecekteki araştırmaların odak noktası olacaktır. Bir MYH'nin performansını artırmak için yüksek kaliteli elektrikjenlerin seçilmesi ve üretilmesi gerekir. MYH’lerde elektrikjenlerin gelecekteki araştırma eğilimleri, elektrokimyasal aktivitelerini iyileştirmek için çok sayıda farklı türlerin taranması, evcilleştirilmesi, modifikasyonu ve optimizasyonu üzerine odaklanmalıdır. Son zamanlarda geliştirilen metabolik mühendislik ve sentetik biyoloji araçları, mevcut elektrik enerjilerini değiştirmek veya mükemmel elektrokimyasal aktivitelere sahip yeni elektrikjen mikroorganizmaları oluşturmak için bu doğrultuda büyük ilgi görmektedir. Genetik modifikasyon kullanılarak, MYH'nin güç çıkışını ve elektroda elektron transferini iyileştirmek için büyük ölçüde keşfedilmemiş potansiyel neredeyse sınırsızdır (Alfonta (2010)). Güç yoğunlukları sadece elektrikjen mikroorganizmalar tarafından değil, MYH'lerin tasarımı (mimarisi), elektrot özellikleri ve elektrolit iletkenliği ile de belirlenir. Bu yönlerdeki gelişmeler aynı zamanda bir MYH'nin elektriksel güç üretim performansının arttırılmasına katkıda bulunacaktır (Cao ve ark. (2019); Chen ve ark. (2019); Çek (2016a); Çek (2017); Erensoy ve Çek (2018); Çek ve Erensoy (2019); Pareek ve ark. (2019)).

MYH teknolojisini ekonomik olarak uygulanabilir kılmak için diğer sistemlerle beraber koordineli çalışabilir hale getirmek gerekmektedir. İlk olarak, atık su arıtımı için MYH kullanılabilir. Atıksu arıtımı için MYH uygulaması mevcut sistemlerin maliyetini düşürmek için cazip bir alternatif olabilir. MYH’lerin ürettiği elektriksel güç, atıksu arıtma biyoreaktörleri için gereken elektrik 
miktarını azaltacaktır (Ahn ve Logan (2013)). İkincisi, MYH aynı anda, saf hidrojen $\left(\mathrm{H}_{2}\right)$ gibi değerli ürünler üretmek için kullanılabilir. Anotta üretilen protonlar $\mathrm{H}_{2}$ oluşturmak için katoda geçebilir. Klasik biyolojik $\mathrm{H}_{2}$ üretim işlemleriyle 4 mol $\mathrm{H}_{2} / \mathrm{mol}$ glikoz üretilmekte iken MYH ile 8-9 mol $\mathrm{H}_{2} / \mathrm{mol}$ glikoz üretilebilir (Liu ve ark. (2005)). Üçüncüsü, elektrikjen mikroorganizmalar çeşitli kimyasalların varlığını ve toksisitesini algılayabilir. Bu nedenle, MYH tabanlı biyosensörler çevresel parametrelerin gerçek zamanlı izlenmesi için uygundur (Schneider ve ark. (2016)). Son olarak, biyoremediasyon (biyolojik iyileştirme) için MYH umut verici bir başka uygulamadır. Aromatik veya ikame edilmiş organik bileşiklerden ağır metallere kadar çeşitli kontaminasyon tiplerinin temizlenmesi için MYH'ler önerilmiştir (Rosenbaum ve Franks (2014)). Biyolojik iyileştirme işlemi sırasında elektrik de üretilir ve böylece elektrik maliyeti azalır. MYH teknolojisinin diğer uygulamalarla birleşimi, MYH'nin olası büyük ölçekli tanıtımının gerçekleşmesine katkı sağlar (Cao ve ark. (2019)).

\section{Kaynakça}

Abrevaya, X. C., Sacco, N., Mauas, P. J. D., Cortón, E., 2011. Archaea-based microbial fuel cell operating at high ionic strength conditions. Extremophiles.15(6), 633-642.

Ahmed, M., Lin, O., Saup, C. M., Wilkins, M. J., Lin, L-S., 2019. Effects of Fe/S ratio on the kinetics and microbial ecology of an Fe(III)-dosed anaerobic wastewater treatment system. Journal of Hazardous Materials, 369, 593-600.

Ahn, Y., Logan, B. E., 2013. Domestic wastewater treatment using multi-electrode continuous flow MFCs with a separator electrode assembly design. Applied Microbiology and Biotechnology, 97, 409-416.

Alfonta, L., 2010. Genetically engineered microbial fuel cells. Electroanalysis, 22, 822-831.

Amano, N., Yamamuro, A., Miyahara, M., Kouzuma, A., Abe, T., Watanabe, K.. 2018. Methylomusa anaerophila gen. nov., sp. nov., an anaerobic methanol-utilizing bacterium isolated from a microbial fuel cell. International Journal of Systematıc and Evolutionary Microbiology, 68(4), 1118-1122.

Borole, A. P., O’Neill, H., Tsouris, C., Cesar, S., 2008. A microbial fuel cell operating at low pH using the acidophile Acidiphilium cryptum. Biotechnology Letters, 30, 1367-1372.

Cao, Y., Mu, H., Liu, W., Zhang, R., Guo, J., Xian, M., Liu, H., 2019. Electricigens in the anode of microbial fuel cells: pure cultures versus mixed communities. Microbial Cell Factories, 18, 14 pages.

Chen, C-Y., Tsai, T-H., Wu, P-S., Tsao, S-E., Huang, Y-S., Chung, Y-C., 2018. Selection of electrogenic bacteria for microbial fuel cell in removing Victoria blue R from wastewater. Journal of Environmental Science and Health, Part A, 53(2), $108-115$.

Chen, S., Patil, S. A., Brown, R. K., Schröder, U., 2019. Strategies for optimizing the power output of microbial fuel cells: Transitioning from fundamental studies to practical implementation. Applied Energy, 233-234, 15-28.

Cho, Y. K., Donohue, T. J., Tejedor, I., Anderson, M.A., McMahon, K. D., Noguera, D. R., 2008. Development of a solar-powered microbial fuel cell. Journal of Applied Microbiology, 104, 640-650.

Çek, N., 2013. Yeni Biyoenerji Tekniğiyle Elektrik Üretilmesi. Çukurova Üniversitesi Mühendislik ve Mimarlık Fakültesi Dergisi, 28(2), 35-49.

Çek, N., 2016a. Parçacıklar ve Enerji Kaynakları. Lambert Academic Publishing, 338 s, Saarbrucken, Almanya.

Çek, N., 2016b. Parçacıklar ve Parçacıkların Enerji Kaynakları Üzerinde Etkileri. Avrupa Bilim ve Teknoloji Dergisi, 4(7), 1-8.

Çek, N., 2017. Examination of zinc electrode performance in microbial fuel cells. Gazi University Journal of Science, 30(4), $395-402$.

Çek, N., Erensoy, A., 2019. Kompost Mikrobiyal Yakıt Hücreleri İçin Titanyum Elektrot Performansının İncelenmesi. Avrupa Bilim ve Teknoloji Dergisi, (17), 909-915.

Erensoy, A., Çek, N., 2018. Alternative Biofuel Materials for Microbial Fuel Cells from Poplar Wood. ChemistrySelect, 3, 125111257.

Evelyn, L., Marshall, A., Gostomski, P. A., 2014. Gaseous pollutant treatment and electricity generation in microbial fuel cells (MFCs) utilising redox mediators. Reviews in Environmental Science and Bio/Technology, 13, 35-51.

Fu, C. C., Hung, T. C., Wu, W. T., Wen, T. C., Su, C. H., 2010. Current and voltage responses in instant photosynthetic microbial cells with Spirulina platensis. Biochemical Engineering Journal, 52, 175-80.

Gomez, M. V., Mai, G., Greenwood, T., Mullins, J. P., 2014. The development and maximization of a novel photosynthetic microbial fuel cell using Rhodospirillum rubrum. Journal of Emerging Investigators, 3, 1-7.

Haavisto, J. M., Lakaniemi, A-M., Puhakka, J. A., 2019. Storing of exoelectrogenic anolyte for efficient microbial fuel cell recovery. Environmental Technology, 40(11), 1467-1475.

Hassani, S. S., Ziaedini, A., Samiee, L., Dehghani, M., Mashayekhi, M., Faramarzi, M. A., 2019. One Step Synthesis of Tertiary Co-doped Graphene Electrocatalyst Using Microalgae Synechococcus elangatus for Applying in Microbial Fuel Cell. Fuel Cells, 19(5), 623-634.

Haslett, N. D., Rawson, F. J., Barriëre, F., Kunze, G., Pasco, N., Gooneratne, R., Baronian, K. H. R., 2011. Characterisation of yeast microbial fuel cell with the yeast Arxula adeninivorans as the biocatalyst. Biosensors and Bioelectronics, 26, 3742-3747.

He, L., Du, P., Chen, Y., Lu, H., Cheng, X., Chang, B., Wang, Z., 2017. Advances in microbial fuel cells for wastewater treatment. Renewable \& Sustainable Energy Reviews, 71, 388-403.

Holmes, D. E., Nicoll, J. S., Bond, D. R., Lovley, D. R., 2004. Potential role of a novel psychrotolerant member of the family Geobacteraceae, Geopsychrobacter electrodiphilus gen. nov., sp. nov., in electricity production by a marine sediment fuel cell. Applied Environmantal Microbiology, 70, 6023-6030.

Hubenova, Y., Mitov, M., 2010. Potential application of Candida melibiosica in biofuel cells. Bioelectrochemistry, 78, 57-61.

Kondaveeti, S., Choi, K. S., Kakarla, R., Min, B., 2014. Microalgae Scenedesmus obliquus as renewable biomass feedstock for electricity generation in microbial fuel cells (MFCs). Frontiers of Environmental Science \& Engineering, 8(5),784-791. 
Lan, J. C. W., Raman, K., Huang, C. M., Chang, C. M., 2013. The impact of monochromatic blue and red LED light upon performance of photo microbial fuel cells (PMFCs) using Chlamydomonas reinhardtii transformation F5 as biocatalyst. Biochemical Engineering Journal, 78, 39-43.

Lapinsonnière, L., Picot, M., Poriel, C., Barrière, F., 2013. Phenylboronic acid modifed anodes promote faster bioflm adhesion and increase microbial fuel cell performances. Electroanalysis, 25, 601-605.

Light, S. H., Su, L., Rivera-Lugo, R., Cornejo, J. A., Louie, A., Iavarone, A. T., Ajo-Franklin, C. M., Portnoy, D. A., 2018. A flavinbased extracellular electron transfer mechanism in diverse Gram-positive bacteria, Nature, 562, 140-144.

Liu, H., Ramnarayanan, R., Logan, B. E., 2004. Production of electricity during wastewater treatment using a single chamber microbial fuel cell. Environmental Science \& Technology, 38, 2281-2285.

Liu, H., Grot, S., Logan, B. E., 2005. Electrochemically assisted microbial production of hydrogen from acetate. Environmental Science \& Technology, 39 4317-4320.

Liu, J., Guo, T., Wang, D., Ying, H. 2015. Clostridium beijerinckii mutant obtained atmospheric pressure glow discharge generates enhanced electricity in a microbial fuel cell. Biotechnology Letters, 37, 95-100.

Liu, Z. D., Li, H. R., 2007. Efects of bio- and abio-factors on electricity production in a mediatorless microbial fuel cell. Biochemical Engineering Journal. 36, 209-214.

Ma, M., Cao, L., Ying, X., Deng, Z., 2012. Study on the performance of photosynthetic microbial fuel cells powered by Synechocystis PCC-6803. Renew. Energy Resour., 30, 42-46.

Malvankar, N. S., Lovley D. R., 2012. Microbial nanowires: a new paradigm for biological electron transfer and bioelectronics. ChemSusChem, 5, 1039-1046.

Ng, FL., Phang, SM., Periasamy, V., Yunus, K., Fisher, A. C., 2014. Evaluation of algal bioflms on indium tin oxide (ITO) for use in biophotovoltaic platforms based on photosynthetic performance. PLoS ONE, 9(5), e97643.

Nielsen, L. P., Risgaard-Petersen, N., Fossing, H., Christensen, P. B., Sayama, M. 2010. Electric currents couple spatially separated biogeochemical processes in marine sediment. Nature, 463, 1071-1074.

Pankratova, G., Hederstedt, L., Gorton, L., 2019. Extracellular electron transfer features of Gram-positive bacteria. Analytica Chimica Acta, 1076, 32-47.

Pareek, A., Sravan, J.S., Mohan, S.V., 2019. Exploring chemically reduced graphene oxide electrode for power generation in microbial fuel cell. Materials Science for Energy Technologies, 2(3), 600-606.

Patil, S. A., Hägerhäll, C., Gorton, L., 2012. Electron transfer mechanisms between microorganisms and electrodes in bioelectrochemical systems. Bioanalytical reviews, 4, 159-192.

Pfeffer, C., Larsen, S., Song, J., Dong, M. D., Besenbacher, F., Meyer, R. L., Kjeldsen, K. U., Schreiber, L., Gorby, Y. A., El-Naggar, M. A., Leung, K. M., Schramm, A., Risgaard-Petersen, N., Nielsen, L. P. 2012. Filamentous bacteria transport electrons over centimetre distances. Nature, 491, 218-221.

Pirbadian, S., El-Naggar, M. Y., 2012. Multistep hopping and extracellular charge transfer in microbial redox chains. Physical Chemistry Chemical Physics, 14, 13802-13808.

Qiao, Y., Wu, X. S., Li, C. M., 2014. Interfacial electron transfer of Shewanella putrefaciens enhanced by nanofaky nickel oxide array in microbial fuel cells. Journal of Power Sources, 266, 226-231.

Raghavulu, S. V., Goud, R. K., Sarma, P. N., Mohan, S. V., 2011. Saccharomyces cerevisiae as anodic biocatalyst for power generation in biofuel cell: infuence of redox condition and substrate load. Bioresource Technology, 102, 2751-2757.

Rosenbaum, M. A., Franks, A. E. 2014. Microbial catalysis in bioelectrochemical technologies: status quo, challenges and perspectives. Applied Microbiology and Biotechnology, 98, 509-518.

Schneider, G., Kovács, T., Rákhely, G., Czeller, M., 2016. Biosensoric potential of microbial fuel cells. Applied Microbiology and Biotechnology, 100, 7001-7009.

Sekar, N., Umasankar, Y., Ramasamy, R. P., 2014. Photocurrent generation by immobilized cyanobacteria via direct electron transport in photobioelectrochemical cells. Physical Chemistry Chemical Physics, 16, 7862-7871.

Shreeram, D. D., Panmanee, W., McDaniel, C. T., Daniel, S., Schaefer, D. W., Hassett, D. J., 2018. Efect of impaired twitching motility and bioflm dispersion on performance of Pseudomonas aeruginosa-powered microbial fuel cells. Journal of Industrial Microbiology \& Biotechnology, 45, 103-109.

Xiang, K., Qiao, Y., Ching, C. B., Li, C. M., 2009. GldA overexpressing-engineered E. Coli as superior electrocatalyst for microbial fuel cells. Electrochemistry Communications, 11, 1593-1595.

Xing, D., Zuo, Y., Cheng, S., Regan, J. M., Logan, B. E., 2008. Electricity generation by Rhodopseudomonas palustris DX-1. Environmental Science \& Technology, 42, 4146-4151.

Xu, C., Poon, K., Choi, M. M. F., Wang, R., 2015. Using live algae at the anode of a microbial fuel cell to generate electricity. Environmental Science and Pollution Research, 22, 15621-15635.

Yi, H., Nevin, K. P., Kim, B. C., Franks, A. E., Klimes, A., Tender, L. M., Lovley, D. R., 2009. Selection of a variant of Geobacter sulfurreducens with enhanced capacity for current production in microbial fuel cells. Biosensors and Bioelectronics, 24, 34983503.

Zhao, F., Slade, R. C. T., Varcoe, J.R. 2009. Techniques for the study and development of microbial fuel cells: an electrochemical perspective. Chemical Society Reviews, 38, 1926-1939.

Zuo, Y., Xing, D., Regan, J. M., Logan, B. E., 2008. Isolation of the exoelectrogenic bacterium Ochrobactrum anthropi YZ-1 by using a U-tube microbial fuel cell. Applied and Environmental Microbiology, 74(10), 3130-3137. 